\title{
INFLUENCIA DO CLORETO DE POTÁSSIO SOBRE O CRESCIMENTO DE COLÓIDES DE SÍLICA
}

Influence of Potassium Chloride on the Growth of Collids of Silica

Influencia del Cloruro de Potasio en el Crecimiento de Coloides de Sílica

Eliciany Ferreira da Silva ${ }^{1}$, Denisia Brito Soares ${ }^{1}$, Alexsandro Silvestre da Rocha ${ }^{* 1}$, Rafael Bento Serpa ${ }^{2}$, Maria Lisa Sartorelli ${ }^{2}$

${ }^{1}$ Laboratório de pesquisa em Materiais para Aplicação em Dispositivos Eletrônicos (LABMADE), Universidade Federal do Tocantins, Araguaína-TO, Brasil.

${ }^{2}$ Laboratório de Sistemas Nanoestruturados (LabSiN), Universidade Federal de Santa Catarina, Florianópolis-SC, Brasil.

*Laboratório de pesquisa em Materiais para Aplicação em Dispositivos Eletrônicos (LABMADE), Universidade Federal do Tocantins, Avenida Paraguai, $s / n^{\circ}$, esquina com a Rua Uxiramas, Setor Cimba, Araguaína, Tocantins, Brasil. CEP: 77.824-838. e-mail alexsandro@uft.edu.br.

Artigo recebido em 08/06/2018 aprovado em 22/01/2019 publicado em 03/12/2019

\section{RESUMO}

A produção de colóides nanométricos possibilitou um grande avanço no ramo da nanotecnologia, com efetiva e potencial aplicação em várias áreas da ciência. Esta evolução só foi possível graças ao desenvolvimento de rotas de síntese química que permitem a fabricação de colóides esféricos monodispersos. Apresentamos a fabricação de colóides de sílica pelo método de Stöber (precipitação de partículas monodispersas por hidrólise de alcóxidos de silício), e a influência da adição de dopante (Cloreto de Potássio) sobre este processo, bem como tipos diferentes de água usada nas sínteses (água purificada por diferentes técnicas). Nota-se pelos resultados de Microscopia Eletrônica de Varredura, que tais parâmetros interferem diretamente na geometria, quantidade e tamanho dos colóides.

Palavras-chave: Colóides de Sílica; Cloreto do Potássio; Síntese.

\section{ABSTRACT}

The production of nanometric colloids has allowed a great advance in the nanotechnology field, with effective and potential application in several areas of science. This evolution was only possible thanks to the development of routes of chemical synthesis that allow the manufacture of spherical monodisperse colloids. We present the manufacture of silica colloids by the Stöber method (precipitation of monodisperse particles by hydrolysis of silicon alkoxides), and the influence of the addition of dopant (Potassium Chloride) on this process, as well as different 
types of water used in the synthesis (water purified by different techniques). It is noted by the results of Scanning Electron Microscopy, that such parameters directly interfere in the geometry, quantity and size of the colloids.

Keywords: Silica Colloids; Potassium Chloride; Synthesis.

\section{RESUMEN}

La producción de coloides nanométricos posibilitó un gran avance en el ramo de la nanotecnología, con efectiva y potencial aplicación en varias áreas de la ciencia. Esta evolución sólo fue posible gracias al desarrollo de rutas de síntesis química que permiten la fabricación de coloides esféricos monodispersos. Se presenta la fabricación de coloides de sílice por el método de Stöber (precipitación de partículas monodispersas por hidrólisis de alcóxidos de silicio), y la influencia de la adición de dopante (Cloruro de Potasio) sobre este proceso, así como diferentes tipos de agua utilizada en las síntesis (agua purificada por diferentes técnicas). Se nota por los resultados de Microscopia Electrónica de Barrido, que tales parámetros interfieren directamente en la geometría, cantidad y tamaño de los coloides

Descriptores: Coloides de Sílice; Cloruro del Potasio; Síntesis.

\section{INTRODUÇÃO}

A habilidade de controlar ou fabricar estruturas em escala nanométrica é conhecida como Nanotecnologia, onde o prefixo nano expressa um fator $10^{-9}$. Esta "nova" ciência ainda em grande ascensão remete-se a década de cinquenta, quando em 1959 o Físico Norte Americano Richard Philips Feynman introduziu o termo Nanomanipulação em uma palestra, afirmando que era possível manipular átomos para confecção de dispositivos (FEYNMAN, 1960). Já a termologia Nanotecnologia, foi proferida pelo engenheiro Japonês e ex-professor da Universidade de Ciências de Tóquio, Norio Taniguchi, que 14 anos após Feynman publicou o artigo intitulado "Sobre o Conceito Básico de NanoTecnologia" (TANAGUCHI, 1974).

Uma dos campos da nanociência é a confecção de colóides nanométricos, que são aplicados na nanoestruturação de materiais (SPADA, 2008-a; SPADA, 2008-b; VOLPATI, 2014; FERBONINK, 2016; AN, 2017), no ramo alimentício (ASSIS, 2012; ARAÚJO, 2015;
ALMEIDA, 2015; MOHR, 2017), medicinal (CHALOUPKA, 2011; HWANG, 2012; YOU, 2012; KIM，2016), odontológico (GIACOMO, 2014), cosméticos (BARIL, 2012; CARVALHO, 2018; SOUZA, 2018), entre outros.

A inovação nestas áreas só foi possível com o desenvolvimento de rotas de síntese química que permitem a fabricação de colóides esféricos monodispersos (STOBER, 1968; BOGUSH, 1988; MURAMATSU, 2004), isto é, com uma distribuição de diâmetros estreita, tipicamente menor que $1 \%$.

Em nosso caso, os colóides sintetizados são aplicados na naoestruturação de materiais explorando processos auto-organizados (SPADA, 2008-a; SPADA, 2008-b; VOLPATI, 2014; FERBONINK, 2016), que é um campo altamente promissor. Há um vasto potencial para a aplicação em dispositivos nanoestruturados em fotônica (YABLONOVITCH, 2001), spintrônica (OHNO, 2016), mídia magnética (ROSS, 1999), supercondutividade (KEMMLER, 2006), catálise e bioengenharia (WHITESIDES, 2002; BATRA, 2005). 
As soluções coloidais monodispersas mais usuais no processo de nanoestruturação são de Poliestireno (PS), Polimetilmetacrilato (PMMA) ou Sílica $\left(\mathrm{SiO}_{2}\right)$, com diâmetros que vão de $50 \mathrm{~nm}$ a 1 $\mu \mathrm{m}$, e podem ser adquiridas comercialmente. Estas soluções geralmente importadas possuem alto custo agregado e podem deteriorar caso o tempo de importação seja longo (transporte), já que dependem de acondicionamento adequado. Uma alternativa à este infortuno é sintetizar tais colóides em laboratório, então neste contexto apresentamos resultados da influência do Cloreto de Potássio $(\mathrm{KCl})$ sobre a sintetização de colóides de Sílica pelo método de Stober, que consiste essencialmente na precipitação de partículas monodispersas de sílica por hidrólise de alcóxidos de silício (STOBER, 1968). O $\mathrm{KCl}$ foi usado aqui apenas com intuito de controlar a condutância da água empregada na síntese.

\section{MATERIAIS E MÉTODOS}

A síntese de colóides de Sílica foi preparada seguindo um processo simples desenvolvido em 1968 pelos pesquisadores Werner Stöber, Arthur Fink e Ernest Bohn (STOBER, 1968), agregando Cloreto de Potássio. Os reagentes, equipamentos e procedimentos adotados podem ser vistos a seguir.

Produtos Químicos: Os reagentes utilizados são constituídos por Álcool Etílico absoluto (25,5\% P.A) da Nuclear, Água $\left(\mathrm{H}_{2} \mathrm{O}\right)$, Tetraetil Ortosilicato (TEOS- 98\%) e Hidróxido de Amônia $\left(\mathrm{NH}_{3} \mathrm{OH}-28 \% \mathrm{NH}_{3}\right.$, P.A) como catalisador da reação, ambos adquiridos da Merck, além do Cloreto de Potássio (99\%) da marca Vetec.

Aparato experimental: A montagem envolve um Condutivímetro de Bancada da MS Tecnopon modelo mCA 150, um reator de plástico (Becker), um Agitador Magnético modelo HI 190M da Hanna Instruments Brasil, uma Centrífuga da marca Centribio Equipamentos Laboratoriais e Hospitalares (modelo 80-2B- 15ML) e uma Lavadora Ultrassônica adquirida da Cristofoli Equipamentos de Biossegurança Ltda.

Purificação de Água: A água usada no processo de síntese deve ser purificada, para tanto utilizou-se sistemas de destilação e Osmose Reversa (OR) da marca Quimis, e sistema de deionização da Union.

Solução de Cloreto de Potássio: $\mathrm{O} \mathrm{KCl}$ é um composto comumente usado na calibração de condutivímetros, e foi utilizado como regulador da condutividade da água empregada na síntese. Para tal conduta, 0,5g de Cloreto de Potássio eram diluídos em $200 \mathrm{ml}$ de água filtrada por OR, criando uma "solução de dopagem" da água com concentração de 2,5g/L. Depois gotas desta solução eram adicionas na água da síntese, agindo como dopante e alterando a condutividade.

Síntese de Colóides de Sílica: Colóides monodispersos de Ś́lica foram sintetizados pelo método de Stöber (1968), onde o crescimento das esferas monodispersas ocorre por hidrólise de silicato e alquila e subsequente condensação de ácido silícico em soluções alcoólicas, sendo a amônia utilizada como catalisador morfológico. Para tanto, apresentamos os reagentes em suas respectivas quantidades: ETANOL: $102,60 \mathrm{ml}, \mathrm{NH}_{4} \mathrm{OH}: 34,18 \mathrm{ml}$, $\mathrm{H}_{2} \mathrm{O}: 8,11 \mathrm{ml}$, TEOS: 5,65ml. A água é dopada com $\mathrm{KCl}$ antes do processo de síntese.

Separação dos Colóides: Ao fim da síntese os colóides são separados dos resíduos por centrifugação, re-dispersos em meio aquoso por ultra-som e armazenados sob refrigeração, resultando na chamada "Solução Coloidal".

Caracterização da Amostras: Nesta etapa, $30 \mu 1$ da Solução Coloidal é disposta sobre um substrato de vidro e posta a secar. Após 24 horas de repouso a $20^{\circ} \mathrm{C}$, as amostras encontram-se prontas 
para análise, que é realizada via Microscópio Eletrônico de Varredura (MEV) disponibilizado na Universidade Federal de Santa Catarina mediante parceria científica com o Laboratório de Sistemas Nanoestruturados. As imagens geradas pela técnica viabilizam a visualização direta da geometria e dimensão dos colóides. Os resultados podem ser vistos a seguir.

\section{RESULTADOS E DISCUSSÃO}

Para melhor entendimento dos resultados, estes serão descritos utilizando tópicos, como segue.

\section{Estudo da Condutividade de Água com}

KCI: Inicialmente analisamos quantas gotas da solução de Cloreto de Potássio a 2,5g/L são necessárias para que a água atinja a condutividade de $5 \mu \mathrm{s} / \mathrm{cm}^{2}$, isto era feito adicionando gradativamente gotas da solução de dopagem e medindo a condutividade $(\sigma)$ com um condutivímetro de bancada. A Figura 01 mostra o gráfico da condutância da água em função do número de gotas do dopante.

Figura 01: Condutância da água relacionada ao número de gotas da solução de dopagem adicionada na água.

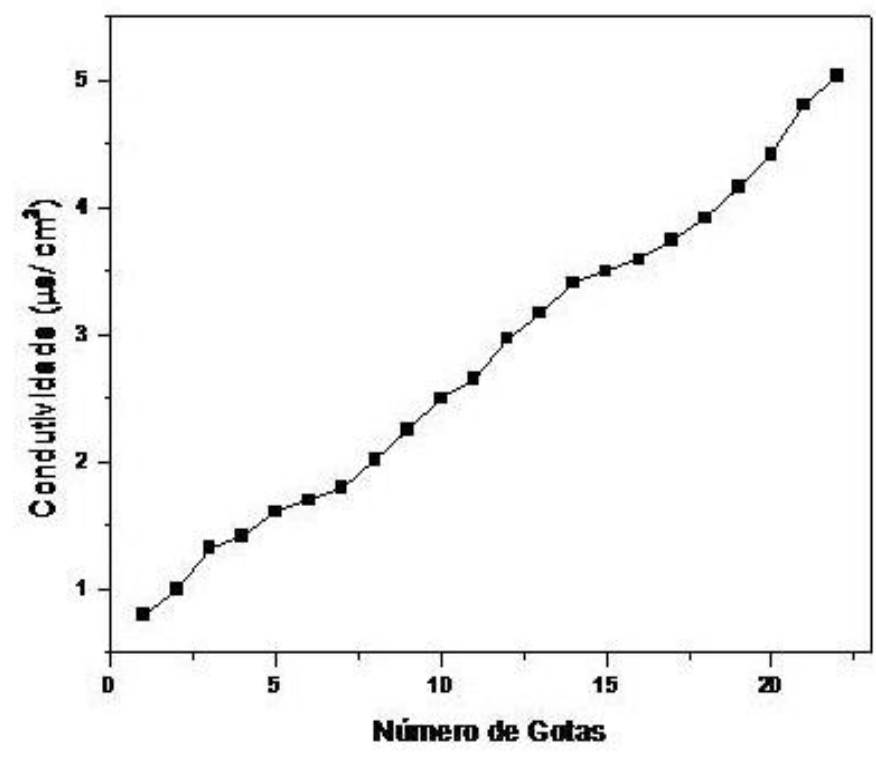

A Figura 01 enfatiza a necessidade de 22 gotas da solução para atingir $5 \mu \mathrm{s} / \mathrm{cm}^{2}$. É possível observar que o aumento da condutividade da água ocorre praticamente de forma linear.

Além de traçar a condutividade da água em função da adição do dopante, também se monitorou a condutância ao longo do tempo, já que o processo de síntese de colóides de sílica pode levar várias horas. A Figura 02 mostra a condutividade da água ao longo de 4:00 horas para a dopagem de $2 \mu \mathrm{s} / \mathrm{cm}^{2}$.

Figura 02: Gráfico da condutividade da água dopada em função do tempo.

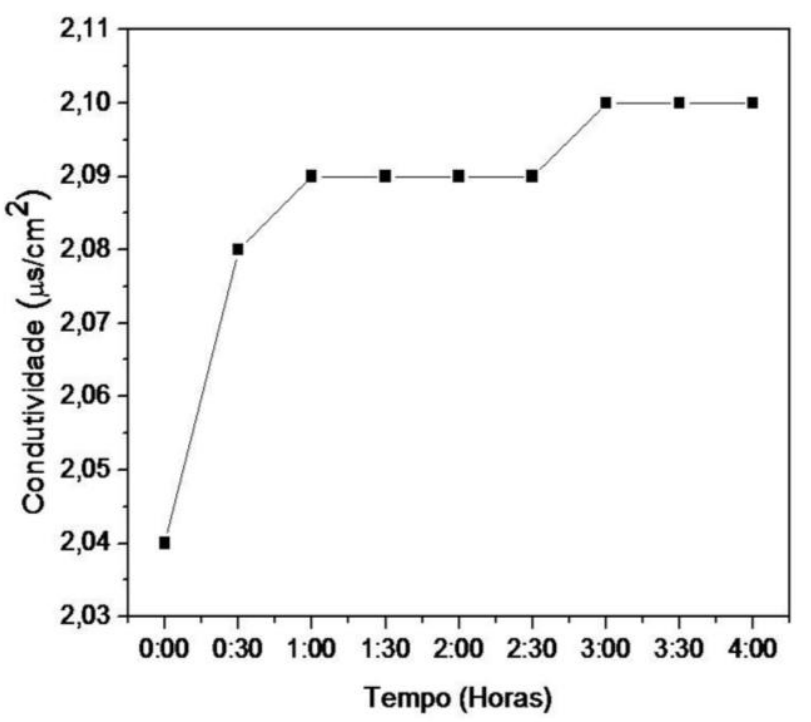

Ao longo do período de teste, a água dopada com $\mathrm{KCl}$ sofreu uma variação aproximada de $0,6 \mu \mathrm{s} / \mathrm{cm}^{2}$, ou seja, uma alteração muito pequena ao compararmos com o longo tempo de síntese dos colóides. Esta mudança acontece praticamente durante a primeira hora, onde a condutividade parte de $2,4 \mu \mathrm{s} / \mathrm{cm}^{2}$ para $2,09 \mu \mathrm{s} / \mathrm{cm}^{2}$, alterando $0,5 \mu \mathrm{s} / \mathrm{cm}^{2}$ neste período. Nas 3:00 horas seguintes a condutância se mantém praticamente estável $(\Delta \sigma=$ $\left.0,01 \mu \mathrm{s} / \mathrm{cm}^{2}\right)$.

\section{Influência do KCl nos Coloides Sintetizados:}

Em relação à dopagem, realizaram-se três sínteses com valores de condutividade da água distintos: $1^{\circ}$ - água sem dopagem com $0,7 \mu \mathrm{s} / \mathrm{cm}^{2}$ (amostra padrão); $2^{\circ}-2 \mu \mathrm{s} / \mathrm{cm}^{2}$ após 8 gotas da solução de dopagem; $3^{\circ}-3 \mu \mathrm{s} / \mathrm{cm}^{2}$ (12 gotas). O 
processo de dopagem consiste em purificar a água que será utilizada nas sínteses, e adicionar a esta gotas da solução de $\mathrm{KCl}$. Cabe ressaltar, que os reagentes e suas respectivas concentrações foram detalhados em Materiais e Métodos. A Figura 03 apresenta as microscopias eletrônicas dos colóides produzidos com os parâmetros supracitados.

Figura 03: Colóides de Sílica sintetizados com água destilada e condutância alterada pelo $\mathrm{KCl}$. (a) Amostra padrão com $0,7 \mu \mathrm{s} / \mathrm{cm}^{2}$ (sem dopante), (b) $2 \mu \mathrm{s} / \mathrm{cm}^{2}$ e (c) $3 \mu \mathrm{s} / \mathrm{cm}^{2}$ alterados pelo dopante.
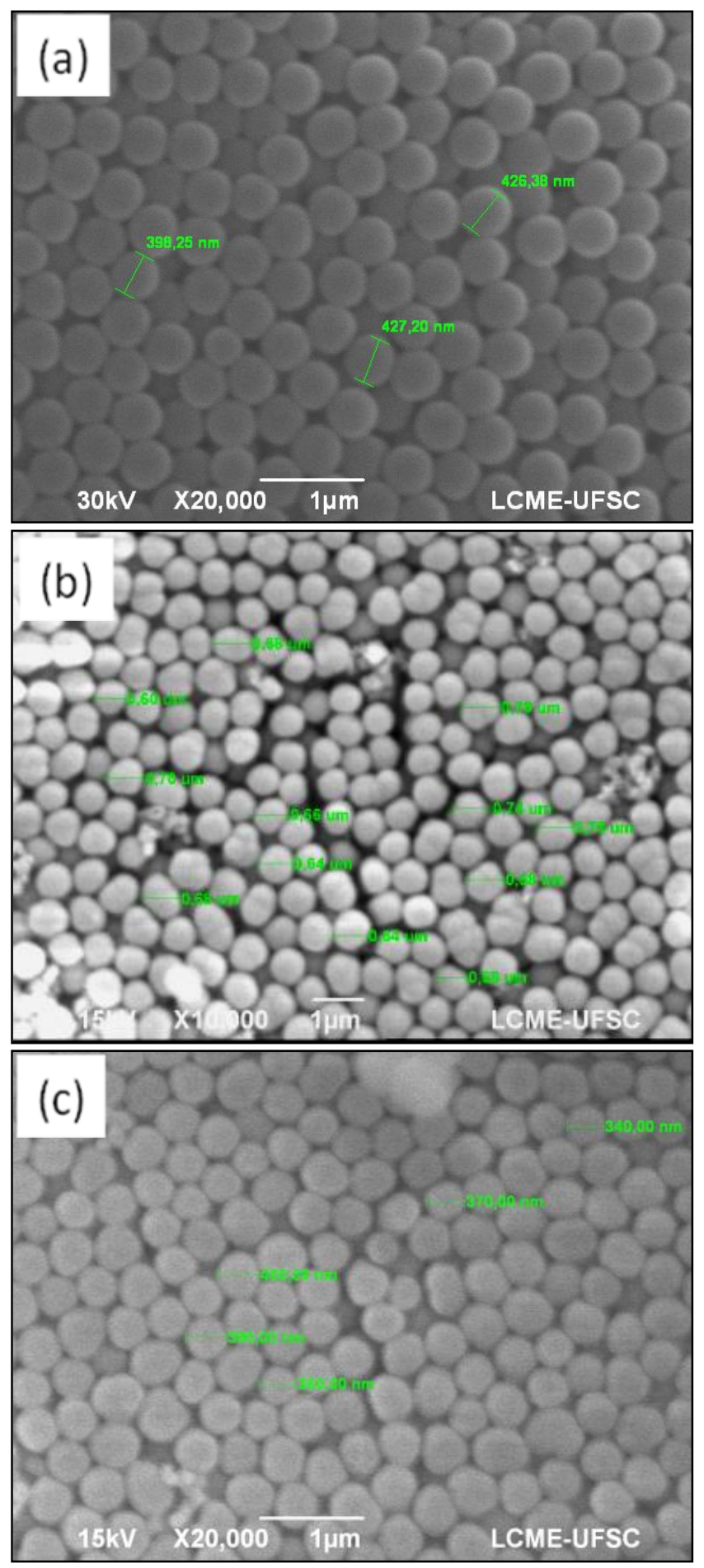

Como é possível observar nas imagens (Figura 03), a adição do Cloreto de Potássio para regular a condutividade da água empregada, altera significativamente o processo de crescimento dos colóides de sílica, ou seja, interferindo na geometria destes, que é fundamental para aplicações tecnológicas. Ao compararmos as amostras com adição de $\mathrm{KCl}$ (Figura 03-b e 03-c) com a padrão (Figura 03-a), fica evidente a deformação dos colóides, pois, enquanto na síntese padrão o formato é esférico, nas demais não temos a mesma qualidade.

As microscopias da Figura 03 também expõe outra perturbação que o Cloreto de Potássio causou no processo de síntese, que é o tamanho dos colóides (ao comparar as Figuras 03-a e 03-b). Com a síntese padrão, o diâmetro varia próximo a 400nm (Figura 03-a), e na amostra dopada para regular a condutividade em $2 \mu \mathrm{s} / \mathrm{cm}^{2}$, este fica próximo a 700nm (Figura 03-b), ou seja, 42\% maior que a amostra controle. Geralmente o tamanho dos colóides é alterado através das concentrações dos reagentes.

\section{Interferência de diferentes tipos de água} (diferentes formas de purificação) sobre as nanoesferas: Outro parâmetro explorado foi à forma de purificação da água usada na síntese, já que esta interfere no crescimento dos colóides (STOBER, 1968). Este trabalho utilizou três técnicas de purificação: A destilação, que utiliza o principio de ebulição e condensação, gerando uma água parcialmente pura, pois não separa completamente as moléculas de $\mathrm{H}_{2} \mathrm{O}$ de todos os sais. A purificação por Osmose Reversa caracteriza-se por usar pressão para forçar a água através de uma membrana que retém as impurezas permitindo que as moléculas de $\mathrm{H}_{2} \mathrm{O}$ passem para o outro lado, sem íons. A deionização, regida pela troca catiônica, que permuta os íons de hidrogênio $(\mathrm{H}+)$ da coluna de troca iônica por contaminantes catiônicos, e pelas trocas de íons 
hidroxila (OH-) por contaminantes aniônicos (trocas aniônicas).

Estas formas de purificar água interferem no resultado final da síntese, sendo expostos nas imagens de MEV apresentadas em sequência. A Figura 04 mostra os resultados de sínteses a partir de água purificada de diferentes fontes, ou seja, utilizouse água Destilada, filtrada por Osmose Reversa e Deionizada depois de filtrada por Osmose Reversa. Vale salientar que a condutividade da água usada (para os três casos) foi mantida a $2 \mu \mathrm{s} / \mathrm{cm}^{2}$ pela adição da solução de KCL.

Figura 04: Resultados para diferentes tipos de purificação de água. (a) Água destilada, (b) água filtrada por Osmose Reversa e Deionizada e apenas (c) água filtrada por OR. Aqui os três tipos de água foram dopadas para atingir condutividade de $2 \mu \mathrm{s} / \mathrm{cm}^{2}$.

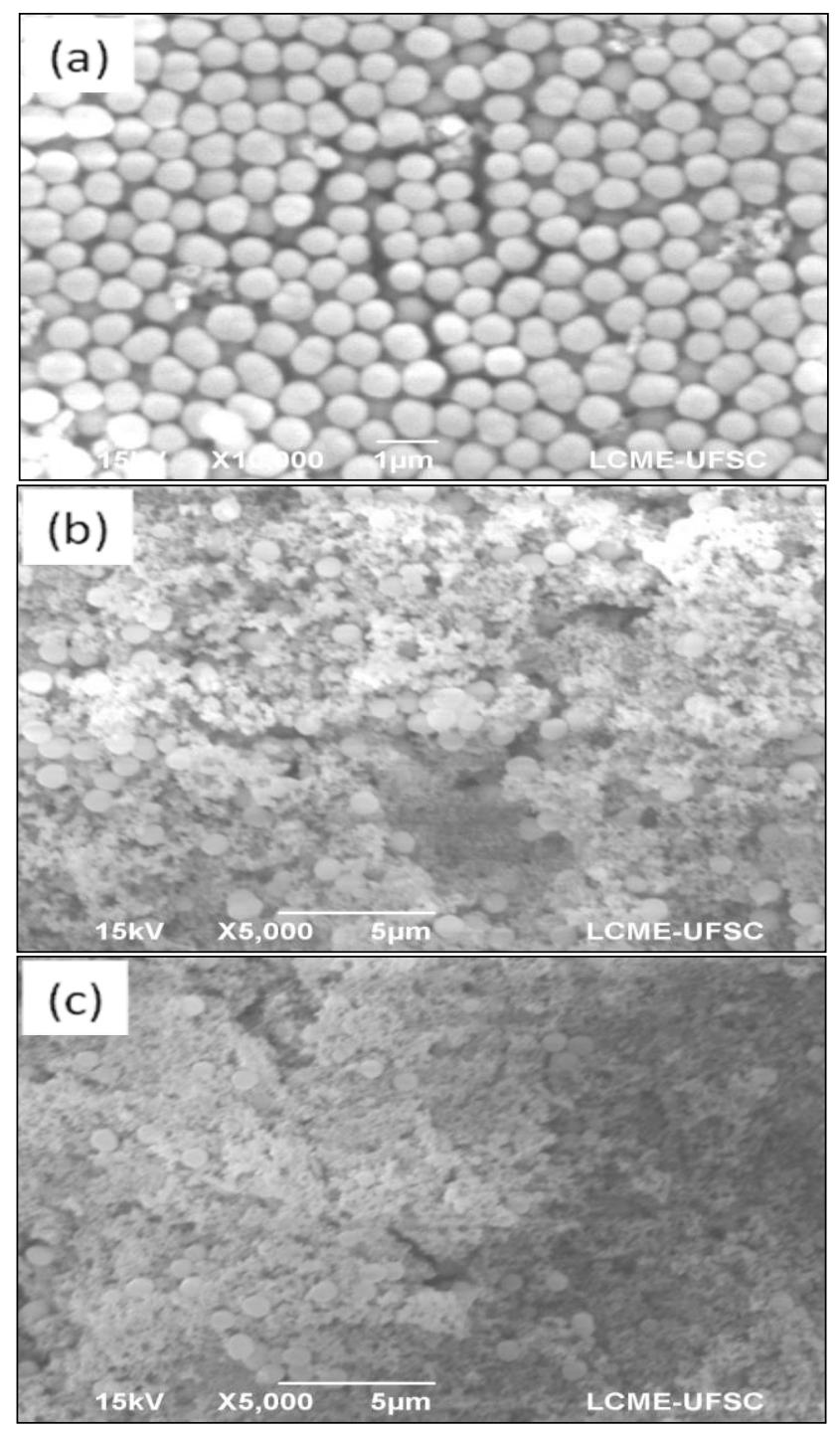

Nota-se pelas microscopias (Figura 04), que as diferentes formas de purificação da água, interferem no processo de crescimento dos colóides. Destaca-se entre elas, a síntese realizada com água destilada (Figura 04-a), é nítida a diferença entre seu resultado e os demais, pois mesmo sem a qualidade desejada, a quantidade de colóides sintetizados é muito superior que as outras. As sínteses que empregaram água filtrada por Osmose Reversa e Deionizada (Figura 03-b) e por Osmose Reversa (Figura 03-c), produziram um número muito pequeno de colóides esféricos, destacados entre resíduos sólidos da síntese ("sementes" não desenvolvidos).

\section{CONCLUSÃO}

Buscou-se produzir colóides de sílica por um método simples a custo viável para aplicação tecnológica e científica. Com o intuito de aprofundar estudos relacionados ao crescimento destes colóides, optou-se em investigar à influência da dopagem da água em tal processo, para tanto, uma solução de dopagem a base de Cloreto de Potássio (empregado na calibração de condutivímetros) foi criada e acrescida ao processo. Os resultados mostram que a adição de $\mathrm{KCl}$ na síntese influencia diretamente na forma, quantidade e tamanho dos colóides. Constatou-se que a dopagem por Cloreto de Potássio causa deformação, interferindo no formato esférico desejado, mas pode ser útil em aplicações odontológicas (por exemplo), pois a forma irregular pode aumentar a abrasão e com isto a eficiência de cremes dentais. Outra informação relevante relaciona o tamanho dos colóides com a condutância da água empregada na síntese, produzindo colóides de sílica $42 \%$ maiores que na síntese padrão, mesmo não alterando as concentrações dos reagentes. Além disto, ao investigar a purificação da água usada no processo, por meio de técnicas que separam as impurezas, conclui-se que a destilação produz um 
número significativo de colóides, quando comparados as técnicas de filtração por Osmose Reversa e Deionização (baixo desenvolvimento dos colóides). A partir das informação adquiridas, almeja-se aprimorar o processo, no intuito de alcançar colóides perfeitamente esféricos.

\section{AGRADECIMENTO}

Os autores agradecem ao Laboratório de pesquisa em Materiais para Aplicação em Dispositivos Eletrônicos (LABMADE) da UFT/Araguaína pelo suporte experimental, o apoio científico do Laboratório de Sistemas Nanoestruturados da Universidade Federal de Santa Catarina, onde as microscopias foram realizadas, e a Universidade Federal do Tocantins.

Todos os autores declararam não haver qualquer potencial conflito de interesses referente a este artigo.

\section{REFERÊNCIAS}

ALMEIDA, A. C. S.; FRANCO, E. A. N.; PEIXOTO, F. M.; PESSANHA, K. L. F.; MELO, N. R. Aplicação de nanotecnologia em embalagens de alimentos. Polímeros, v.25 (número especial), 89-97, 2015 .

AN, W.; FU, J.; SU, J.; WANG, L.; PENG, X.; WU, K.; CHEN, Q.; BI, Y.; GAO, B.; ZHANG, X. Mesoporous hollow nanospheres consisting of carbon coated silica nanoparticles for robust lithium-ion battery anodes. Journal of Power Sources, v.345, p. 227-236, 2017.

ARAÚJO, E. A.; RIBEIR, L.; BERNARDES, P. C.; DORES, M. T.; JÚNIOR, J. F. Q. F. Sanitização de cenoura minimamente processada com nanopartículas de prata. Ciência Rural, v.45(9), p.1681-1687, 2015.
ASSIS, L. M.; ZAVAREZE, E. R; PRENTICEHERNÁNDEZ， C.; SOUZA-SOARES， L. A. Revisão: Características de nanopartículas e potenciais aplicações em alimentos. Brazilian Journal Food Technology, v.15(2), p. 99-109, 2012.

BARIL, M. B.; FRANCO, G. F.; VIANA, R. S.; ZANIN, S. M. W. Nanotecnologia Aplicada aos Cosméticos. Visão Acadêmica, v.13(1), p. 45-54, 2012.

BATRA, D.; VOGT, S.; LAIBLE, P.D.; FIRESTONE, M.A. "Self-assembled mesoporous polymeric networks for patterned protein arrays". Langmuir, v.21, p.10301, 2005.

BOGUSH, G. H.; TRACY, M.A.; ZUKOSKI, C.F. "Preparation of monodisperse silica particles: control of size and mass fraction", Journal Non-Crystalline solids, v.104, p. 95-106, 1988.

CARVALHO, L. P. (2018). Nanotecnologia Aplicada à Dermocosmética. Dissertação. Mestrado Integrado em Ciências Farmacêuticas. Universidade Lusófona de Humanidades e Tecnologias/Escola de Ciências e Tecnologias da Saúde. Lisboa.

CHALOUPKA K. MALAM Y. SEIFALIAN A. Review: nanosilver as a new generation of nanoproduct in biomedical applications. Trends in Biotechnology, v. 28(11), p. 580-588, 2011.

FERBONINK, G. F.; SPADA, E. R.; SANTOS, D. P.; SARTORELLI, M. L.; NOME, R. A. . Ultrafast Dynamics of $\mathrm{Au}$ Nanopyramid Interfaces Prepared by Nanosphere Lithography: Effect of Substrate Chemical Composition. Journal of the Brazilian Chemical Society (Impresso), v. 27, p. 423-433, 2016.

FEYNMAN, R. P. There's Plenty of Room at the Bottom R. Caltech's Engineering and Science, v. 23(5), p.22-36, 1960. 
GIACOMO, V. D.; COMAR, L. P.; SALOMÃO, P. M. A.; MAGAlHÃES, A. C. Efeito de pasta com nanopartículas de hidroxiapatita e fluoreto sobre a desmineralização da dentina. Revista da Associação Paulista de Cirurgiões Dentista. v.68(2), p.112-116, 2014.

HWANG I.; LEE J.; HWANG J.; KIM K.; LEE D. Silver nanoparticles induce apoptotic cell death in Candida albicans through the increase of hydroxyl radicals. The FEBS Journal, v. 279(7), p.13271338. 2012.

KEMMLER, M.; GURLICH, C.; et al. "Commensurability effects in superconducting $\mathrm{Nb}$ films with quasiperiodic pinning arrays". Physical Review Letters, v. 97, 147003, 2006.

KIM, MH. Nanoparticle-Based Therapies for Wound Biofilm Infection: Opportunities and Challenges. IEEE Transactions on Nanobioscience, v. 15(3), p.294-304, 2016

MOHR, L. C.; CAPELEZZO, A. P.; RIPPEL, T.; TERNUS, R. Z.; DALCANTON, F.; FIORI, M. A.; MELLO, J. M. M. Efeito antimicrobiano de nanopartículas de $\mathrm{ZnO} \mathrm{E} \mathrm{TiO} 2$ frente as bactérias $\mathrm{S}$. aureus e E. coli. Revista CSBEA, v.3(1), p.1-10, 2017.

MURAMATSU, L. V. Obtenção de Partículas Micrométricas para Máscaras de Litografia. Laboratório Nacional de Luz Síncrotron, Relatório Final PIBIC - 2004. Orientado por D. ZANCHET.

NAFEE, N.; YOUSSEF, A.; EL-GOWELLI, H.; ASEM, H.; KANDIL, S. Antibiotic-free nanotherapeutics: Hypericin nanoparticles thereof for improved in vitro and in vivo antimicrobial photodynamic therapy and wound healing.

International Journal of Pharmaceutics, v.454(1), p.249-258, 2013
OHNO, H.; STILES, M. D.; DIENY, B. Spintronics. Proceedings of the IEEE. Institute of Electrical and Electronics Engineers, v.104(10), p.1782-1786, 2016.

ROSS, C. A.; SMITH, H. I.; SAVAS, T.; et al. "Fabrication of patterned media for high density magnetic storage", Journal of Vacuum Science \& Technology. v.17 p.3168, 1999.

SOUZA, H. S. V. (2018). Efeito de nanopartículas de óxido de zinco e do sulfato de zinco no cladócero tropical Ceriodaphnia silvestrii. Dissertação. Programa de Pós-Graduação em Ecologia e Recursos Naturais. Universidade Federal de São Carlos. São Carlos.

SPADA, E. R.; PEREIRA, G. M.; JASINSKI, E. F.; da ROCHA, A. S.; SCHILLING, O. F.; SARTORELLI, M. L. Anisotropic magnetoresistance in electrodeposited cobalt antidot arrays. Journal of Magnetism and Magnetic Materials, v. 320, p. e253e256, 2008 - a.

SPADA, E. R.; da ROCHA, A. S.; JASINSKI, E. F.; PEREIRA, G. M.; CHAVERO, L. N.; OLIVEIRA, A.; AZEVEDO, A.; SARTORELLI, M. L. Homogeneous growth of antidot structures electrodeposited on $\mathrm{Si}$ by nanosphere lithography. Journal of Applied Physics, v. 103, p. 114306-1114306-5, 2008 - b.

STOBER, W.; FINK, A.; BOHN, E. Controlled Growth of Monodisperse Silica Spheres in Micron Size Range. Journal Colloid and Interface Science, v.26, p.62-69, 1968.

TANIGUCHI, N. "On the Basic Concept of 'NanoTechnology'," International Conference on Production Engineering, Tokyo Part II, Japan Society of Precision Engineering, 1974.

VOLPATI, D.; SPADA, E. R.; CID, C. C. P. ;SARTORELLI, M. L.; AROCA, R. F.; 
CONSTANTINO, C. J. L. Exploring copper nanostructures as highly uniform and reproducible substrates for plasmon-enhanced fluorescence. Analyst (London. 1877. Print), v. 140, p. 476-482, 2014.

YABLONOVITCH, E. "Photonic crystal: semiconductors of light", Scientific American, v 285. p 47-51, 2001.

YOU C. HAN C. WANG X. ZHENG Y. LI Q. HU $X$. et al. The progress of silver nanoparticles in the antibacterial mechanism, clinical application and cytotoxicity. Molecular Biology Reports, v.39(9), p.9193-9201, 2012.

WHITESIDES, G. M.; BONCHEVA, M. "Supramolecular chemistry and self-assembly beyond molecules: Self-assembly of mesoscopic and macroscopic components", Proceedings of the National Academy of Sciences, v.99, p. 4769-4774, 2002. 